\title{
Production of Oil-Free Crunchy Potato Chips Using Microwave
}

\author{
Naglaa A. Shedeed ${ }^{1,2^{*}}$, El-Sayed A. Abd El-Hady ${ }^{1,3}$, Rehab A. ALoweis ${ }^{1}$ \\ ${ }^{1}$ Food Science and Human Nutrition Department, College of Agriculture and Veterinary Medicine, Qassim University, \\ Buraidah, Kingdom of Saudi Arabia \\ ${ }^{2}$ Food Science Department, National Research Center, Dokki, Giza, Egypt \\ ${ }^{3}$ Department of Hotel Studies, Faculty of Tourism and Hotels, Suez Canal University, Ismailia, Egypt \\ Email: *naaly@qu.edu.sa
}

How to cite this paper: Shedeed, N.A., El-Hady, E.S.A.A. and Aloweis, R.A. (2020) Production of Oil-Free Crunchy Potato Chips Using Microwave. Food and Nutrition Sciences, 11, 40-51.

https://doi.org/10.4236/fns.2020.111005

Received: November 28, 2019

Accepted: January 14, 2020

Published: January 17, 2020

Copyright $\odot 2020$ by author(s) and Scientific Research Publishing Inc. This work is licensed under the Creative Commons Attribution International License (CC BY 4.0).

http://creativecommons.org/licenses/by/4.0/

\begin{abstract}
The study was conducted to evaluate the effect of baking conditions of partially-dried potato slices (PDPS) prior baking on the quality attributes of the resultant baked potato chips. Baking experiment was conducted at power levels of 80 and 100 Watts for different baking times according to microwave power used. Texture, color measurements and sensory evaluation were carried out on resultant baked potato chips. The results showed that partially drying step (even to $40 \%$ moisture content) prior microwave baking resulted in marked crispiness as well as brilliant yellow in resultant potato chips. The optimum conditions for the best quality of partially-dried potato chips were microwave cooking at power level of 100 Watts for 100 seconds.
\end{abstract}

\section{Keywords}

Potato Chips, Pre-Drying, Microwave Baking, Baking Time, Sensory Properties

\section{Introduction}

Traditional Potato crisps have an oil content that ranges from 30\% to $45 \%$ (wet basis) that gives the product the unique and desirable texture-flavor combination [1]. Potato chips texture is often described in terms of crispness, hardness and crunchiness. This crispy/crunchy character is an important sensory characteristic on which consumer's acceptance [2]. In recent years, increasing consumer awareness of the relationship between nutrition and health has led to the demand for high quality foods that are also healthy [3]. Hence, Fried products are facing friction towards its adaptation by health and calorie-conscious people 
which is commonly known as dietary restraint. Therefore, there is earnest need to develop low or free fat potato chips with good sensory quality for widening the scope of its acceptance [4]. Use of microwave baking for food products may be considered as a new way of improving the quality of the foods. Baking is considered as a viable alternative to frying due to its potential to provide a similar product with no added fat [5], and baked version of potato chips has been marketed by several manufacturers [6]. Consumer preference for low-fat products has been the driving force of this food industry to produce lower oil content fried potatoes that still retain the desirable texture and flavor. Many approaches to reduce oil absorption and improve the quality of fried foods during the frying process, due to demands of consumers for low-fat and healthy food [7] [8]. Potato has been pretreated prior to frying and has shown improved quality in terms of low oil content, crispness, flavor, color and nutritional contents [9]. Pre-drying (even to $40 \%$ moisture content) pretreatment had positive effect on the quality attributes of potato chips [10]. Microwave processing can be an alternative technology for the development of potato chips with low or no intake of oil [11].

The present study was undertaken to develop a new microwave condition to produce free-oil potato chips using microwave. The influence of microwave cooking conditions at power levels of 80 and 100 watt was evaluated. The microwave process was applied on partially dried potato slices. Furthermore, sensorial analysis, texture and color measurements of produced potato chips were evaluated.

\section{Materials and Methods}

\subsection{Material}

Fresh potatoes (tubers of Solanum tuberosum L.), cultivar Hermes were used for this experiment. This cultivar was grown at Qassium region, Saudi Arabia. Potato tubers purchased from one of the local farm in Al-Qassim region. Refined table salt (Ressa brand) was purchased from a local market, Al-Qassim, Saudi Arabia. All chemicals used for the present study were of analytical grade and bought from Sigma Chemical Company (St. Louis, USA).

\subsection{Potato Slices Preparation}

Potato tubers were selected, washed and brushed thoroughly with clean water. Potatoes were peeled with sharp knife and immersed in $\mathrm{NaCl}$ solution $2 \%$. Potatoes were sliced into thickness $1.5 \mathrm{~mm}$ using an electric slicing machine (Philips, model HR7761). The potato slices were immediately rinsed with distilled water. Sliced potatoes were blanched in hot water at $85^{\circ} \mathrm{C} \pm 5^{\circ} \mathrm{C}$ for 3 min, followed by immersing in potassium metabisulphite solution for $15 \mathrm{~min}$ then, the slices were drained [12]. Samples were partially dried in hot air oven dryer at $60^{\circ} \mathrm{C} \pm 1^{\circ} \mathrm{C}$ to reduce potato moisture content even to $40 \%$ of its initial value [10]. 


\subsection{Microwave Baking Experiments}

Microwave processing of potato chips was performed in a domestic digital microwave oven (Samsung CE104VD, Malaysia). The partially dried potato slices (PDPS) and non-dried ones (control) (WPD) were baked at different microwave power levels (80 Watts for 100, 120 and $140 \mathrm{sec}$. and 100 Watts for 80, 100 and $120 \mathrm{sec}$.). The potato chips were placed side by side on a dish in the microwave so that they would not stick together. Finally, the microwaved baked potato chips (MBPC) were cooled, packed and further qualitative analysis was conducted. Experiments were conducted in parallel. Three replications of each experiment were performed according to a preset microwave output power and time schedule.

\subsection{Determination of Some Quality Properties of Baked Potato Chips}

\section{Surface color measurement}

The colors of the samples were measured by Hunter color meter (Hunter Associates Lab Inc. (Model No: LabScan XE, USA) in terms of Hunter parameters $\left(L^{*}, a^{*}\right.$ and $\left.b^{\star}\right)$ in order to investigate the color changes of potato chips as affected by different microwave power levels and baking times according to method [13].

\subsection{Texture Analysis}

Textural properties of the microwave baked potato chips (MBPC) were performed at room temperature $\left(\sim 25^{\circ} \mathrm{C} \pm 1^{\circ} \mathrm{C}\right)$ by employing puncture test, with slight modifications [14]. The measurements were performed by using a computer-assisted determined by using the Brookfield TA XT-Plus Texture Analyzer (USA) with a 5-kg-load cell. Beaked chips were mounted individually on a three-point-support, at a distance maintained at $15 \mathrm{~mm}$ with the punch diameter and the cross-head speed being $2 \mathrm{~mm}$ and $60 \mathrm{~mm} / \mathrm{min}$, respectively. Force versus distance curves was generated based on the puncture test and data was analyzed by using inbuilt software of the texture analyzer.

\subsection{Sensory Evaluation of Microwave Baked Potato Chips}

Potato chips samples were evaluated for their all sensory attributes including textural attributes by 10 semi-trained panelists, on 9-point Hedonic scale, where 9 and 1 represented liked extremely and disliked extremely, respectively. The microwave baked potato chips samples (MBPC) were evaluated by 20 panelists from Food Science Department, Faculty of Agriculture and Veterinary Medicine, Al-Qassim University, Saudi Arabia. The panelists marked their preference on a 10-Point Hedonic Scale (1-Dislike extremely, 5-Neither like nor dislike and 9, 10-Like extremely) in accordance with their opinion for color, taste, odour, texture, appearance and overall acceptability [15]. 


\subsection{Statistical Analysis}

All the data were subjected to statistical analysis using Analysis of Variance (ANOVA) according to Armitage and Berry [16].

\section{Results and Discussion}

\subsection{Effect of Microwave Baking at Power Level of $80 \mathrm{~W}$ for 100 , 120 and 140 Sec. on the Quality Parameters of Baked Potato Chips}

\subsubsection{The Color Coordinates of the Resultant Potato Chips}

The color of potato chips is considered as a key evaluation factor of products quality which yielded from Millard reaction. The color of baked samples was measured in terms of the parameters $\left(L^{\star}, a^{\star}\right.$, and $\left.b^{\star}\right)$ to investigate the color changes of potato chips as affected by pre-drying pretreatment and microwave conditions were shown in Table 1 . Color parameter $L^{*}$ (lightness) of WPD and PDPS were significantly different for 100 and $140 \mathrm{sec}$. baking times. No significantly different differences were found for $120 \mathrm{sec}$. Where the $L^{*}$ values of both samples were almost equal. It may be due to the fact that pre-drying step or baking did not induce browning much as it inhibited enzymatic action responsible for browning rapidly [16]. Lightness $\left(L^{*}\right)$ value of PDPS for $100 \mathrm{sec}$. was lower $(70.58 \pm 0.24)$ than their WPD $(74.30 \pm 0.06)$, while $L^{*}$ value was higher $(64.46 \pm 0.25)$ than their WPD $(55.52 \pm 0.28)$ baked at $80 \mathrm{~W}$ for $140 \mathrm{~s}$. Therefore, MBPC, which was actually non-pre-dried, did not show any sign of enzymatic browning during microwave cooking process.

As a result of baking, the $a^{*}$ (redness) coordinate value increases from negative values in WPD and PDPSat power level of $80 \mathrm{~W}$ for $100 \mathrm{sec}$. $(-3.20 \pm 0.01$ and $-2.91 \pm 0.06)$, to values which become greater when increasing the baking time 140 sec. $(+4.15 \pm 0.09 ;+3.17 \pm 0.07)$. In general, $a^{*}$ value increases with increasing baking time at power level of $80 \mathrm{~W}$. These changes in the $a^{*}$ coordinate occur as a result of the Millard reaction, generating compounds that give brownish tones [17].

Table 1. Effect of microwave baking at power level of 80 Watts for 100, 120 and $140 \mathrm{sec}$. on the colour attributes of potato chips.

\begin{tabular}{ccccc}
\hline \multirow{2}{*}{ baking time (sec.) } & Treatments & \multicolumn{3}{c}{ Color coordinates } \\
\cline { 3 - 4 } & & $L^{*}$ & $a^{*}$ & $b^{*}$ \\
\hline \multirow{2}{*}{100} & WPD & $74.30 \pm 0.06^{\mathrm{a}}$ & $-3.02 \pm 0.01^{\mathrm{c}}$ & $26.82 \pm 0.22^{\mathrm{a}}$ \\
& PDPS & $70.58 \pm 0.24^{\mathrm{b}}$ & $-2.91 \pm 0.06^{\mathrm{c}}$ & $25.78 \pm 0.13^{\mathrm{b}}$ \\
\multirow{2}{*}{120} & WPD & $67.38 \pm 0.184^{\mathrm{c}}$ & $3.07 \pm 0.04^{\mathrm{b}}$ & $26.48 \pm 0.28^{\mathrm{a}}$ \\
& PDPS & $67.10 \pm 0.06^{\mathrm{c}}$ & $-0.79 \pm 0.05^{\mathrm{d}}$ & $24.67 \pm 0.21^{\mathrm{c}}$ \\
& WPD & $55.52 \pm 0.28^{\mathrm{e}}$ & $4.15 \pm 0.09^{\mathrm{a}}$ & $21.53 \pm 0.27^{\mathrm{d}}$ \\
& PDPS & $64.46 \pm 0.25^{\mathrm{d}}$ & $3.17 \pm 0.07^{\mathrm{b}}$ & $25.03 \pm 0.02^{\mathrm{c}}$ \\
\hline
\end{tabular}

${ }^{*}$ Values are the mean \pm SD (Standard deviation) of ten replicate experiments $(n=10)$; ${ }^{*}$ Means with different superscript in the column are significantly different at $\mathrm{P} \leq 0.05$. WPD: Control (without pre-drying). PDPS: Partially dried potato slices (even to $40 \%$ of its initial moisture content). 
The results showed that the baking times at $80 \mathrm{~W}$ had significant effects on the values of $b^{\star}$ between WPD and PDPS (Table 3). When cooking for 100 and $120 \mathrm{sec}$, the PDPS were given less value than in the control, while for $140 \mathrm{sec}$. the value of $b^{*}$ for PDPS was higher $(25.03 \pm 0.02)$ than the control $(21.53 \pm$ 0.27). According to [17], the high $b^{\star}$ values are desirable for fried potato products. These results are in agreement with [18] and [19]. An increase in the $b^{*}$ value was also observed in pre-drying step drying with different baking time for 80 Watts. This shows change in colour towards yellowness. This increase might be developed from an increase of carotenoid content per unit weight during drying [20].

\subsubsection{The Texture Properties of Resultant Potato Chips}

The most significant textural property of frying or baking product is crispness, which indicates freshness and quality. The breaking force is used as an indicator of the low or high crispy of the fried potato slices. A higher hardness value indicates that material requires a higher force treatment for breaking and this can be explained as brittle of potato slices in this investigation [21].

The results shown in Figure 1 show the texture of the MBPC on the power level of $80 \mathrm{~W}$ for 100, 120 and $140 \mathrm{sec}$. It can be seen in Figure 1 that the breaking force of baked potato chips at cooking power level $80 \mathrm{~W}$ increased with the baking time. Moreover, there are differences between the texture of the PDPS and WPD when baked at $80 \mathrm{~W}$ for $100 \mathrm{sec}$. When cooking for $120 \mathrm{sec}$., the breaking force of the partially dried chips was lower than WPD ones. However, the control chips were less soft and drier compared to the cooking time of 100 sec. but they were non-brittle, not just break and therefore it bends only. At indicates that microwave heating at power level of $80 \mathrm{~W}$ has the potential to produce the chips from PDPS after $120 \mathrm{sec}$. of processing without addition of fat. The crispy texture was obtained by tissue consisting of air cavities surrounded by a brittle structural phase [22]. According to the results, PDPS had less flexible texture. At the baking, the breaking force of potato chips with PDPS is lower than that WPD. While the breaking force of potato chips with PDPS is higher than that of WPD ones. When the pre-dried potato chips baked, the internal moisture will evaporate more rapidly, and this would create a high vapor pressure and the shrinkage of baked product would result in the reduction of the breaking force [23] suggested that the breaking force of products can be appropriately affected by the duration of pre-drying. These results are in agreement with those reported by [24] reported that the drying time, microwave power and cooking time have a significant impact on texture of potato chips. [25] found that the hardness of fried potato chips can be used to reflect the crispness, and lower value of hardness corresponding to better crispness.

\subsubsection{The Sensory Evaluation of Potato Chips}

Scores for the sensory properties of the microwave baked at power level of $80 \mathrm{~W}$ for different baking times of potato chips are given in Table 2 and Figure 2. It was observed that, the PDPS, for either 100 or $120 \mathrm{sec}$, gave higher values in all 


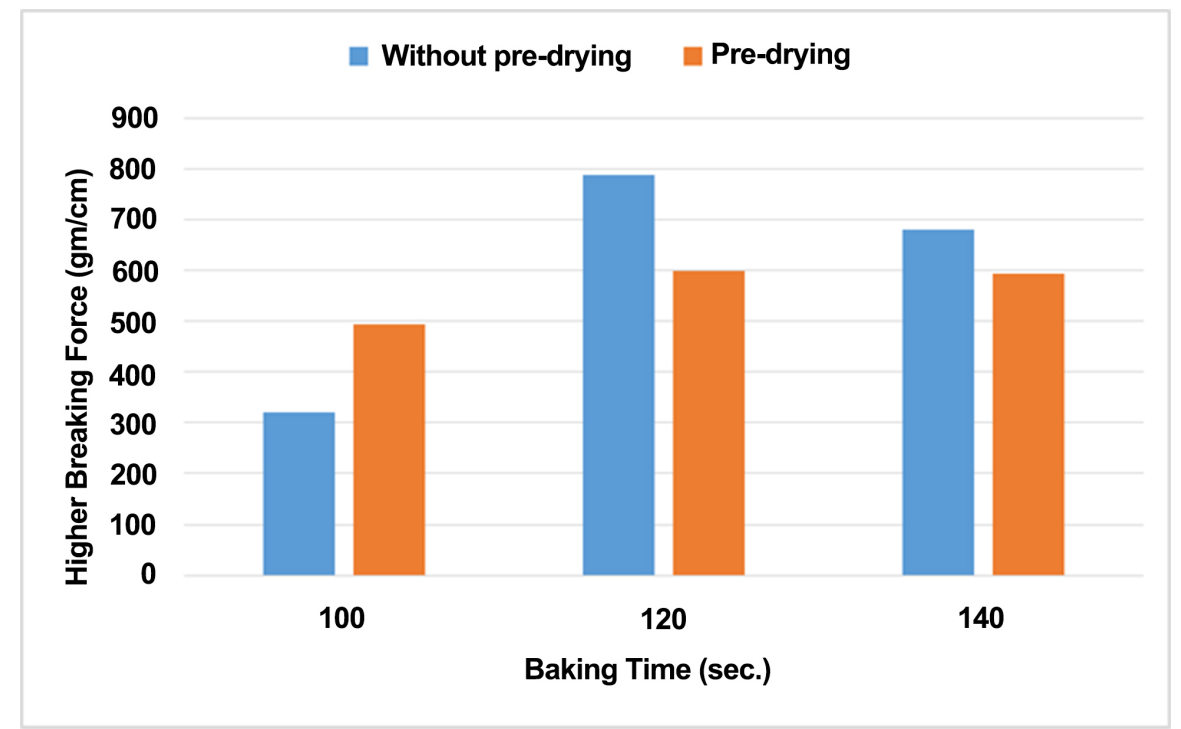

Figure 1. Effect of microwave baking at power level of $80 \mathrm{~W}$ for 100, 120 and $140 \mathrm{sec}$. on texture $(\mathrm{gm} / \mathrm{cm})$ of the potato chips.

Table 2. The effect of microwave baking at power level of $80 \mathrm{~W}$ for 100, 120 and 140 sec. on the sensory characteristics of the potatoes chips.

\begin{tabular}{cccccccc}
\hline Baking time (sec.) & Treatments & Color & Odor & Taste & Texture & Appearance & Overall acceptability \\
\hline \multirow{2}{*}{100} & WPD & $7.64 \pm 0.36^{\mathrm{ab}}$ & $7.27 \pm 0.30^{\mathrm{a}}$ & $6.36 \pm 0.20^{\mathrm{c}}$ & $6.00 \pm 0.43^{\mathrm{b}}$ & $7.09 \pm 0.29^{\mathrm{ab}}$ & $6.27 \pm 0.19^{\mathrm{c}}$ \\
& PDPS & $8.18 \pm 0.35^{\mathrm{a}}$ & $7.91 \pm 0.28^{\mathrm{a}}$ & $7.55 \pm 0.31^{\mathrm{ab}}$ & $7.73 \pm 0.38^{\mathrm{a}}$ & $7.91 \pm 0.34^{\mathrm{a}}$ & $7.91 \pm 0.32^{\mathrm{a}}$ \\
& WPD & $7.82 \pm 0.40^{\mathrm{ab}}$ & $7.36 \pm 0.47^{\mathrm{a}}$ & $7.36 \pm 0.39^{\mathrm{abc}}$ & $7.36 \pm 0.45^{\mathrm{a}}$ & $8.09 \pm 0.29^{\mathrm{a}}$ & $7.27 \pm 0.27^{\mathrm{abc}}$ \\
\multirow{2}{*}{120} & PDPS & $8.09 \pm 0.32^{\mathrm{a}}$ & $8.18 \pm 0.23^{\mathrm{a}}$ & $8.09 \pm 0.25^{\mathrm{a}}$ & $8.27 \pm 0.14^{\mathrm{a}}$ & $8.18 \pm 0.29^{\mathrm{a}}$ & $8.18 \pm 0.23^{\mathrm{a}}$ \\
& WPD & $6.64 \pm 0.43^{\mathrm{b}}$ & $7.27 \pm 0.62^{\mathrm{a}}$ & $7.45 \pm 0.43^{\mathrm{ab}}$ & $7.64 \pm 0.59^{\mathrm{a}}$ & $7.36 \pm 0.34^{\mathrm{ab}}$ & $7.55 \pm 0.37^{\mathrm{ab}}$ \\
& PDP & $6.82 \pm 0.55^{\mathrm{b}}$ & $7.27 \pm 0.47^{\mathrm{a}}$ & $6.55 \pm 0.43^{\mathrm{bc}}$ & $7.18 \pm 0.44^{\mathrm{ab}}$ & $6.45 \pm 0.55^{\mathrm{b}}$ & $6.73 \pm 0.57^{\mathrm{bc}}$ \\
\hline
\end{tabular}

Each value represents the parameter mean value from 20 panelists. Overall quality of fried potato chips was rated a 10-point scale. The overall quality scale was 1-Dislike extremely, 5-Neither like nor dislike and 9,10-Like extremely. Means with different superscript in the column are significantly different at $P \leq 0.05$. WPD: Control (without pre-drying). PDPS: Partially dried potato slices (even to $40 \%$ of its initial moisture content).

sensory characteristics, color, odor, taste, texture, appearance and overall acceptability compared to WPD ones for the same baking period. But, when baking for $140 \mathrm{sec}$. where control chips recorded higher values than PDPS in sensory properties such as taste, texture, appearance and overall acceptability. The results showed that the PDPS and baked for $120 \mathrm{sec}$. at 80 watts obtained the highest values of all sensory characteristics compared to the other baked chips for 100 and $140 \mathrm{sec}$. Thus, microwave processing at power level of $80 \mathrm{~W}$ for 120 sec. was suitable to process the potato chips with acceptable sensory scores $\left(8.18^{\mathrm{a}}\right.$ \pm 0.23 on 10-points on hedonic scale). Therefore, it is recommended should not exceed baking time $120 \mathrm{sec}$. when using power level of $80 \mathrm{~W}$ for producing of good quality of potato chips from PDPS. Thus, the sensory evaluation of potato chips by combined pre-drying step and microwave condition revealed that this technology could be an alternative frying technology for producing baked prod- 
uct with a better quality and high consumer acceptance.

As can be seen in Figure 2, the MBPC got higher color quality score than that in WPD samples. The results of color quality score remind that a longer processing time would lead to larger color change. While pre-drying method could also achieve better color quality products than WPD. For overall acceptability, the baked samples produced by MBPC ( $80 \mathrm{~W}$ for $120 \mathrm{sec}$.) got the highest score (Table 2). The higher texture quality score would relate to a crisper texture quality. The results of sensory scores are in agreement with the results of quality analysis.

\subsection{Effect of Microwave Baking at Power Level of $100 \mathrm{~W}$ for $\mathbf{8 0}$, 100 and 120 Sec. on the Quality Parameters of Baked Potato Chips}

\subsubsection{The Colour Coordinates of the Resultant Potato Chips}

Experimental data of color parameters of PDPS cooking at power level $(100 \mathrm{~W})$ and baking times $\left(80,100\right.$ and $120 \mathrm{sec}$.) are shown in Table 3 . The $L^{*}, a^{*}$ and $b^{*}$ values of PDPS for all baking times were lower than the WPD baked in microwave. Effect of microwave baking time was significant on $L^{*}, a^{*}$ and $b^{*}$ values.

As shown in Table 3, the lightness of potato chips decreased with increasing baking time in all samples during microwave baking. A higher $L^{*}$ values indicate a lighter color, which is desirable in these products. A similar trend was reported in the microwave frying process of potato chips [25] [26]. Color parameter $L^{\star}$ of WPD and PDPS were significantly different for all baking times. Lightness $\left(L^{*}\right)$ value of PDPS was lower than their WPD. The $a^{*}$ (redness) values increased with increasing baking time at power level of $100 \mathrm{~W}$ for both control WPD and PDPS (Table 3). At constant power level $100 \mathrm{~W}$, the $a^{*}$ (greenness) decreased with pre-drying step in baking time (80 and $100 \mathrm{sec}$.). At baking time $120 \mathrm{sec}$., the $a^{*}$ (redness) value increased with treated potato chips with pre-drying step.

The $b^{*}$ (yellowness), there are significant differences between the PDPS and the WPD among the baking time. The PDPS gave less value compared to the WPD for all baking times (Table 3 ). Although, increases in $a^{*}$ and decreases in $b^{*}$ values of PDPS was higher than non-dried microwave bakedones, the highest $L^{*}, a^{*}, b^{*}$ values obtained in microwave treatment because the shorter time
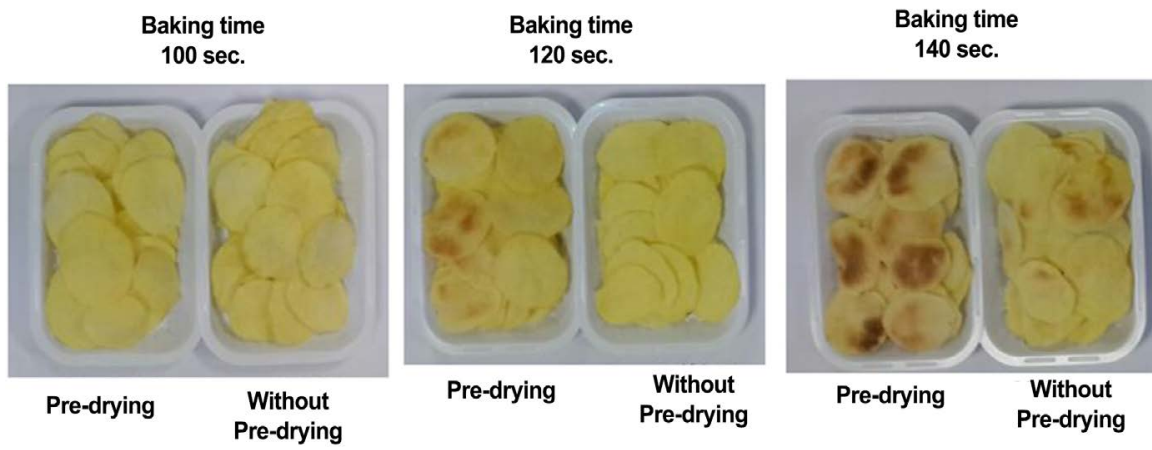

Figure 2. Images of potato slices baked at power level of $80 \mathrm{~W}$ for 100, 120 and $140 \mathrm{sec}$. 
Table 3. Effect of microwave baking at power level of 100 Watts for 80,100 and $120 \mathrm{sec}$. on the color attributes of potato chips.

\begin{tabular}{ccccc}
\hline \multirow{2}{*}{ Baking time (sec.) } & Treatments & \multicolumn{3}{c}{ Color coordinates } \\
\cline { 3 - 5 } & & $L^{*}$ & $a^{*}$ & $b^{*}$ \\
\hline \multirow{2}{*}{80} & WPD & $73.11 \pm 0.05^{\mathrm{a}}$ & $-2.90 \pm 0.06^{\mathrm{d}}$ & $23.73 \pm 0.19^{\mathrm{bc}}$ \\
& PDPS & $63.64 \pm 0.15^{\mathrm{e}}$ & $-1.54 \pm 0.02^{\mathrm{c}}$ & $22.78 \pm 0.13^{\mathrm{c}}$ \\
\multirow{2}{*}{100} & WPD & $68.37 \pm 0.04^{\mathrm{c}}$ & $-2.19 \pm 0.06^{\mathrm{d}}$ & $27.12 \pm 0.05^{\mathrm{a}}$ \\
& PDPS & $65.15 \pm 0.06^{\mathrm{d}}$ & $-0.43 \pm 0.02^{\mathrm{b}}$ & $18.25 \pm 0.03^{\mathrm{e}}$ \\
& WPD & $69.18 \pm 0.07^{\mathrm{b}}$ & $-0.45 \pm 0.01^{\mathrm{b}}$ & $23.95 \pm 0.03^{\mathrm{b}}$ \\
\hline & PDPS & $57.06 \pm 0.03^{\mathrm{f}}$ & $0.40 \pm 0.01^{\mathrm{a}}$ & $18.80 \pm 0.12^{\mathrm{d}}$ \\
\hline
\end{tabular}

Values are the mean \pm SD (Standard deviation) of ten replicate experiments $(n=10)$. Means with different superscript in the column are significantly different at $P \leq 0.05$. WPD: Control (without pre-drying). PDPS: Partially dried slices (even to $40 \%$ of its initial moisture content).

required for baking was not sufficient for completion of the Maillard reaction. Microwave treatment provides the opportunity to obtain fat-free products. Based on the obtained $L^{*}, a^{*}$ and $b^{*}$ indices, it can be stated that the best (bright) colour was characteristic of potato chips obtained from potato slices partially-dried (even to $40 \%$ of its initial moisture content), while the least appropriate (dark colour) was that of potato chips made of slices that were left without pre-drying. The values of $L^{*}, a^{*}$ and $b^{*}$ values decreased continuously. Colour of microwaved potato chips after $100 \mathrm{sec}$. of microwave processing at $100 \mathrm{~W}$ can be described as slight creamish yellow $\left(L^{*}: 65.15 ; a^{*}:-043 ; b^{*}: 18.25\right)$ (Table 3 ). Unfortunately, excessive baking time may result in negative effects on products quality [20]. Moreover, lower $L^{*}$ value is also responsible for non-enzymatic browning reactions [1].

\subsubsection{The Texture Properties of Resultant Potato Chips}

Table 4 shows the results of the texture determination in the microwave-baked potato chips at power level of 100 Watts for different cooking times (80, 100 and $120 \mathrm{sec}$.). The results showed that no significant difference between WPD and PDPS at $P \leq 0.05$ baking at power level of 100 watts for 120 sec., $\left(654.8^{\mathrm{b}} \pm 20.43\right.$ and $678.4^{\mathrm{b}} \pm 26.43$ ) but the control slices were rigid (hard) and non-brittle. However, potato chips obtained from potato strips without pre-dried (control) exhibited harder texture compared with those obtained from potato slices pre-dried prior baking. This may be due to pre-drying as pretreatment of the potato slices and its effect on the texture. The drying time increases the texture and increases the breaking force gradually [24].

\subsubsection{The Sensory Evaluation of Resultant Potato Chips}

The sensory scores of baked potato chips by different microwave baking condition (power level of 100 watts for 80,100 and 120 s) are shown in Table 5 and Figure 3. The overall acceptability of samples as a representative of all sensory characteristics, there was a significant difference at $P \leq 0.05$ between control and 
Table 4. Effect of microwave baking at power level of 100 watts for 80,100 and $120 \mathrm{sec}$. on the texture of potato chips (gm/cm).

\begin{tabular}{cccc}
\hline \multirow{2}{*}{ Treatment } & \multicolumn{3}{c}{ Baking time (sec.) } \\
\cline { 2 - 4 } & $\mathbf{8 0}$ & 100 & 120 \\
\hline WPD & $129.60 \pm 4.23^{\mathrm{c}}$ & $839.3 \pm 36.22^{\mathrm{a}}$ & $654.80 \pm 20.43^{\mathrm{b}}$ \\
PDPS & $677.10 \pm 11.17^{\mathrm{b}}$ & $800.00 \pm 35.15^{\mathrm{a}}$ & $678.40 \pm 26.43^{\mathrm{b}}$ \\
\hline
\end{tabular}

Values are the mean $\pm \mathrm{SD}$ (Standard deviation) of ten replicate experiments $(n=10)$. Means with different superscript in the column are significantly different at $P \leq 0.05$. WPD: Control (without pre-drying). PDPS: Partially dried slices (even to $40 \%$ of its initial moisture content).

Table 5. The effect of microwave baking at power level of 100 watts for 80,100 and 120 sec. on the sensory characteristics of the resultant potatoes chips.

\begin{tabular}{cccccccc}
\hline Baking time (sec.) & Treatments & Color & Odor & Taste & Texture & Appearance & Overall acceptability \\
\hline \multirow{2}{*}{80} & WPD & $7.40^{\mathrm{a}} \pm 0.43$ & $6.80^{\mathrm{a}} \pm 0.44$ & $6.10^{\mathrm{c}} \pm 0.38$ & $5.70^{\mathrm{c}} \pm 0.42$ & $7.10^{\mathrm{b}} \pm 0.41$ & $6.00^{\mathrm{d}} \pm 0.39$ \\
& PDPS & $8.20^{\mathrm{a}} \pm 0.33$ & $7.40^{\mathrm{a}} \pm 0.43$ & $6.90^{\mathrm{bc}} \pm 0.51$ & $7.20^{\mathrm{ab}} \pm 0.59$ & $7.90^{\mathrm{ab}} \pm 0.38$ & $7.30^{\mathrm{bc}} \pm 0.42$ \\
\multirow{2}{*}{100} & WPD & $7.90^{\mathrm{a}} \pm 0.35$ & $7.10^{\mathrm{a}} \pm 0.46$ & $6.20^{\mathrm{c}} \pm 0.51$ & $6.50^{\mathrm{bc}} \pm 0.52$ & $7.20^{\mathrm{b}} \pm 0.49$ & $6.50^{\mathrm{cd}} \pm 0.34$ \\
& PDPS & $8.50^{\mathrm{a}} \pm 0.34$ & $8.10^{\mathrm{a}} \pm 0.23$ & $8.30^{\mathrm{a}} \pm 0.26$ & $8.40^{\mathrm{a}} \pm 0.22$ & $8.50^{\mathrm{a}} \pm 0.27$ & $8.90^{\mathrm{a}} \pm 0.23$ \\
\multirow{2}{*}{120} & WPD & $7.90^{\mathrm{a}} \pm 0.35$ & $8.00^{\mathrm{a}} \pm 0.33$ & $8.10^{\mathrm{ab}} \pm 0.41$ & $8.00^{\mathrm{a}} \pm 0.33$ & $8.00^{\mathrm{ab}} \pm 0.33$ & $8.20^{\mathrm{ab}} \pm 0.25$ \\
& PDPS & $5.60^{\mathrm{b}} \pm 0.65$ & $6.80^{\mathrm{a}} \pm 0.59$ & $6.10^{\mathrm{c}} \pm 0.61$ & $7.10^{\mathrm{ab}} \pm 0.55$ & $5.10^{\mathrm{c}} \pm 0.53$ & $6.10^{\mathrm{d}} \pm 0.61$ \\
\hline
\end{tabular}

Each value represents the parameter mean value from 20 panelists. Overall quality of fried potato chips was rated a 10-point scale. The overall quality scale was 1-Dislike extremely, 5-Neither like nor dislike and 9, 10-Like extremely. ${ }^{*}$ Means with different superscript in the column are significantly different at $P \leq 0.05$. WPD: Control (without pre-drying). PDPS: Partially dried slices (even to $40 \%$ of its initial moisture content).
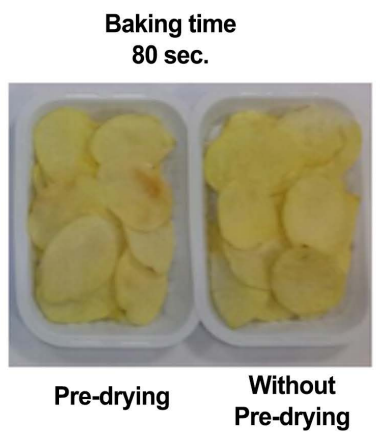
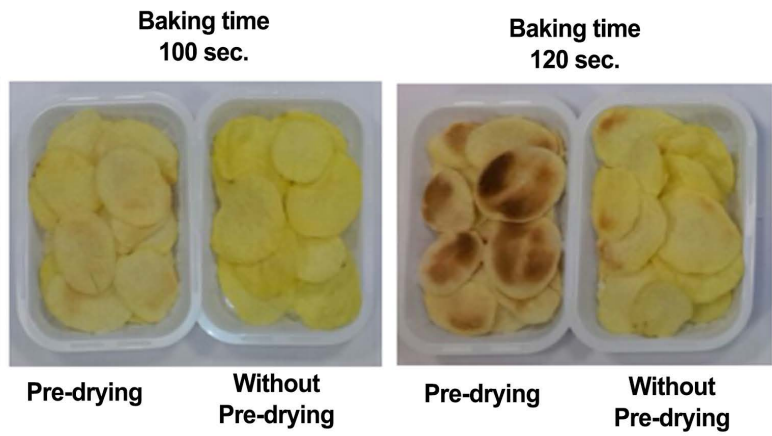

Figure 3. Images of potato slices baked at power level of 100 Watts for 80,100 and 120 sec.

partially-dried samples for 80,100 and $120 \mathrm{sec}$. We note that the partially dried potato chips prior baked for $100 \mathrm{sec}$. at 100 Watts obtained the highest values of all sensory characteristics compared to the rest of the other slices. The baked potato chips by microwave got higher color quality score than that in untreated samples, while got higher color quality score than that pre-dried for $120 \mathrm{sec}$. The higher texture quality score would relate to a crisper texture quality. The samples pre-dried up to $40 \%$ would achieve higher texture quality score than the control samples expect for $120 \mathrm{sec}$.

For overall acceptability, the baked samples produced by pre-drying got the highest score at $100 \mathrm{~W}$ for $100 \mathrm{sec}$. In the overall acceptability standing product 
Table 6. Sensory Evaluation of Selected treatments ${ }^{\star}$ MBPC baked by different microwave power levels $(80$ and $100 \mathrm{~W})$ for, 120 and $100 \mathrm{sec}$.

\begin{tabular}{cccccccc}
\hline $\begin{array}{c}\text { Microwave } \\
\text { power level (W) }\end{array}$ & $\begin{array}{c}\text { Baking } \\
\text { time (sec.) }\end{array}$ & Color & Odor & Taste & Texture & Appearance $\begin{array}{c}\text { Overall acceptabil- } \\
\text { ity }\end{array}$ \\
\hline $\mathbf{8 0}$ & 120 & $8.44 \pm 0.37^{\mathrm{a}}$ & $8.16 \pm 0.26^{\mathrm{a}}$ & $8.29 \pm 0.28^{\mathrm{a}}$ & $8.46 \pm 0.19^{\mathrm{a}}$ & $8.59 \pm 0.29^{\mathrm{a}}$ & $8.59 \pm 0.19^{\mathrm{b}}$ \\
100 & 100 & $8.64 \pm 0.47^{\mathrm{a}}$ & $8.01 \pm 0.31^{\mathrm{a}}$ & $8.47 \pm 0.29^{\mathrm{a}}$ & $8.48 \pm 0.19^{\mathrm{a}}$ & $8.78 \pm 0.34^{\mathrm{a}}$ & $9.28 \pm 0.18^{\mathrm{a}}$ \\
\hline
\end{tabular}

Overall quality of fried potato chips was rated a 10-point scale. The overall quality scale was 1, 2 bad; 3, 4 poor; 5, 6 fair; 7, 8 good; 9, 10 excellent. Means with different superscript in the column are significantly different at $P \leq 0.05$. MBPC: microwave baked potato chips.

baked at $100 \mathrm{~W}$ for $100 \mathrm{sec} .\left(8.90^{\mathrm{a}} \pm 0.23\right)$ in microwave were the most desirable ones. The sensory evaluation of potato chips revealed that baking technology could be an alternative frying technology for producing fried product with a better quality and high consumer acceptance.

\subsection{The Final Sensory Evaluation of the PDPS Microwaved at Two Power Levels (80 and 100 Watts) for 120 and $100 \mathrm{Sec}$.}

Sensory evaluation scores for selected baked potato chips is presented in Table 6. There was no-significant differences in sensory attributes; color, odor, taste, texture and appearance between the two selected treatments. There are significant different was found between baked potato chips at power level $80 \mathrm{~W}$ for 120 sec. in overall acceptability and that those baked at $100 \mathrm{~W}$ for $100 \mathrm{sec}$. For overall acceptability, microwave processing ( $100 \mathrm{~W}$ for $100 \mathrm{sec}$.) was found suitable for processing of potato chips with overall acceptability sensory scores $\left(9.28^{\mathrm{a}} \pm\right.$ 0.18 on 10-points on hedonic scale). Thus, the sensory evaluation of potato chips at power level $100 \mathrm{~W}$ for $100 \mathrm{sec}$. revealed that this technology could be an alternative frying technology for producing fried product with a better quality and high consumer acceptance.

\section{Conclusion}

According to the results, it can be concluded the treatment combination of 100 $\mathrm{W}$ and $100 \mathrm{sec}$. to PDPS was found to be the best in terms of color, taste, texture, appearance and overall acceptability and for the production of free fat potato chips. Finally, it could be said that baked potato chips can be used to produce low calorie snack foods. Thus, microwave baking could be recommended as an alternative to deep fat frying.

\section{Conflicts of Interest}

The authors declare no conflicts of interest regarding the publication of this paper.

\section{References}

[1] Abong, O., Okoth, W., Jasper, K., Imungi, K. and Kabira, N. (2011) Effect of Slice Thickness and Frying Temperature on Color, Texture and Sensory Properties of Crisps Made from Four Kenyan Potato Cultivars. American Journal of Food Tech- 
nology, 6, 753-762. https://doi.org/10.3923/ajft.2011.753.762

[2] Gaikwad, K.Y. and Athmaselvi, K.A. (2016) Effect of Soaking Pre-Treatments on Different Characteristics of Fried Potato Chips. Biosciences Biotechnology Research Asia, 13, 1133-1136. https://doi.org/10.13005/bbra/2142

[3] Pandey, A. and Singh, G. (2011) Development of Reduced Sugar Soy Containing Compound Chocolate and Its Storage Study. Journal of Food Science and Technology, 48, 76-82. https://doi.org/10.1007/s13197-010-0136-8

[4] Oladejo, A., Ma, H., Qu, W., Zhou, C., Wu, B., Uzoejinwa, B., Onwudeb, D. and Yanga, X. (2018) Application of Pretreatment Methods on Agricultural Products Prior to Frying: A Review. Journal of the Science of Food and Agricultural, 98, 456-466. https://doi.org/10.1002/jsfa.8502

[5] Palazoglu, T., Savran, D. and Gokmen, V. (2010) Effect of Cooking Method (Baking Compared with Frying) on Acrylamide Level of Potato Chips. Journal of Food Science, 75, 25-29. https://doi.org/10.1111/j.1750-3841.2009.01389.x

[6] Kapadiya, D.C., Makavana, J.M. and Kathiria, M.K. (2018) Effect of Hot Water Blanching Treatment on Quality of Dried Potato Slices. International Journal Current Microbiology Applied Sciences, 7, 2754-2764.

https://doi.org/10.20546/ijcmas.2018.707.322

[7] Moreira, R.G., Da Silva, P.F. and Gomes, C. (2009) The Effect of a De-Oiling Mechanism on the Production of High Quality Vacuum Fried Potato Chips. Journal Food Engineering, 92, 297-304. https://doi.org/10.1016/j.jfoodeng.2008.11.012

[8] Tarmizi, A.H. and Niranjan, K. (2010) The Possibility of Lowering Oil Content of Potato Chips by Combining Atmospheric Frying with Post-Frying Vacuum Application. Journal of Food Science, 75, E572-E579.

https://doi.org/10.1111/j.1750-3841.2010.01819.x

[9] Kim, D., Lim, J., Bae, I., Lee, H. and Lee, S. (2011) Effect of Hydrocolloid Coatings on the Heat Transfer and Oil Uptake during Frying of Potato Strips. Journal Food Engineering, 102, 317-320. https://doi.org/10.1016/j.jfoodeng.2010.09.005

[10] AbdEl-Hady, E.A., ALoweis, R.A. and Shedeed, N.A. (2018) A Study on the Effect of Per-Drying Technique on Fried Potato Chips Quality. Journal of Agricultural and Veterinary Sciences Qassim University, 11, 225-241.

[11] Tuta, S. and Palazoğlu, T. (2017) Effect of Baking and Frying Methods on Quality Characteristics of Potato Chips. The Journal of Food, 42, 43-49. https://doi.org/10.15237/gida.GD16050

[12] Suh, H., Cho, Y., Chung, M. and Kim, B. (2007) Preliminary Data on Sulphite Intake from the Korean Diet. Journal of Food Composition and Analysis, 20, 212-219. https://doi.org/10.1016/j.jfca.2006.04.012

[13] Sliburyte, L. and Skeryte, I. (2014) What We Know about Consumers' Color Perception. Procedia-Social and Behavioral Sciences, 156, 468-472. https://doi.org/10.1016/j.sbspro.2014.11.223

[14] Segnini, S., Dejmek, P. and Ơste, R. (1999) Reproducible Texture Analysis of Potato Chips. Journal of Food Science, 64, 309-312. https://doi.org/10.1111/j.1365-2621.1999.tb15889.x

[15] Carpenter, R., Lyon, D. and Hasdell, T. (2000) Guidelines for Sensory Analysis in Food Product Development and Quality Control. Aspen Publishers, Inc., Gaithersburg, 71-91. https://doi.org/10.1007/978-1-4615-4447-0

[16] Armitage, P. and Berry, G. (1987) Statistical Methods, Method in Medical Research. Blackwell, Oxford. 
[17] Pedreschi, F., Mery, D. and Marique, T. (2016) Chapter 22 Quality Evaluation and Control of Potato Chips A2. In: Sun, D.-W., Ed., Computer Vision Technology for Food Quality Evaluation, 2nd Edition, Academic Press, San Diego, 591-613. https://doi.org/10.1016/B978-0-12-802232-0.00022-0

[18] Sotome, I., Takenaka, M., Koseki, S., Ogasawara, Y., Nadachi, Y., Okadome, H. and Isobe, S. (2009) Blanching of Potato with Superheated Steam and Hot Water Spray. LWT-Food Science and Technology, 42, 1035-1040. https://doi.org/10.1016/j.lwt.2009.02.001

[19] Bingol, G., Wang, B., Zhang, A., Pan, Z. and McHugh, T. (2014) Comparison of Water and Infrared Blanching Methods for Processing Performance and Final Product Quality of French Fries. Journal of Food Engineering, 121, 135-142. https://doi.org/10.1016/j.jfoodeng.2013.08.001

[20] Mierzwa, D. and Pawłowski, A. (2017) Convective Drying of Potatoes Assisted by Microwave and Infrared Radiation Process Kinetics and Quality Aspects. Journal of Food and Nutrition Research, 56, 351-361.

[21] Al-Faruq, A., Zhang, M., Khatum, H. and Azam, S. (2018) Application of Microwave-Assisted Vacuum Frying on Frying Apple Slices. International Research Journal Biological Science, 7, 13-22.

[22] Scaman, C. and Durance, T. (2005) Emerging Technologies for Food Processing. Elsevier Academic Press, London, 768.

[23] Wang, L., Zhang, M., Fang, Z. and Xu, B. (2014) Application of Intermediate-Wave Infrared Drying in Preparation of Mushroom Chewing Tablets. Drying Technology, 32, 1820-1827. https://doi.org/10.1080/07373937.2014.949347

[24] Kothakota, A., Thimmaiah, B., Yadav, K. and Panday, J. (2013) Development of Microwave Baked Potato Chips Using Tomato Flavor. Asian Journal of Agriculture and Food Science, 1, 246-260.

[25] Su, Y., Zhang, M., Zhang, W., Adhikari, B. and Yang, Z. (2016) Application of Novel Microwave-Assisted Vacuum Frying to Reduce the Oil Uptake and Improve the Quality of Potato Chips. LWT_Food Science and Technology, 73, 490-497. https://doi.org/10.1016/j.lwt.2016.06.047

[26] Su, Y., Zhang, M. and Zhang, W. (2015) Effect of Low Temperature on the Microwave-Assisted Vacuum Frying of Potato Chips. Drying Technology, 34, 227-234. https://doi.org/10.1080/07373937.2015.1040027 